\title{
Nonoperative care to manage sacroiliac joint disruption and degenerative sacroiliitis: high costs and medical resource utilization in the United States Medicare population
}

\author{
Clinical article
}

\author{
Stacey J. Ackerman, Ph.D., ${ }^{1}$ David W. Polly Jr., M.D., ${ }^{2}$ Tyler Knight, M.S., ${ }^{3}$ \\ Tim Holt, M.D., ${ }^{4}$ AND John Cummings JR., M.D. ${ }^{5}$ \\ ${ }^{1}$ Covance Market Access Services Inc., San Diego, California $;{ }^{2}$ Departments of Orthopaedic Surgery and \\ Neurosurgery, University of Minnesota, Minneapolis, Minnesota; ${ }^{3}$ Covance Market Access Services Inc., \\ Gaithersburg, Maryland; ${ }^{4}$ Montgomery Spine Center, Orthopedic Surgery, Montgomery, Alabama; and \\ ${ }^{5}$ Community Health Network, Neurosurgery, Indianapolis, Indiana
}

\begin{abstract}
Object. Low-back pain (LBP) is highly prevalent among older adults, and the cost to treat the US Medicare population is substantial. Recent US health care reform legislation focuses on improving quality of care and reducing costs. The sacroiliac (SI) joint is a recognized generator of LBP, but treatments traditionally have included either nonoperative medical management or open SI joint fusion, which has a high rate of complications. New minimally invasive technologies have been developed to treat SI joint disruption and degenerative sacroiliitis, so it is important to understand the current cost impact of nonoperative care to the Medicare program. The objective of this study was to evaluate the medical resource use and associated Medicare reimbursement for patients managed with nonoperative care for degenerative sacroiliitis/SI joint disruption.

Methods. A retrospective study was conducted using claim-level data from the Medicare 5\% Standard Analytical Files (SAFs) for the years 2005-2010. Included were patients with a primary ICD-9-CM (International Classification of Diseases, Ninth Revision, Clinical Modification) diagnosis code for degenerative sacroiliitis/SI joint disruption (ICD-9-CM diagnosis codes 720.2, 724.6, 739.4, 846.9, or 847.3) with continuous enrollment for at least 1 year before and 5 years after diagnosis. Claims attributable to degenerative sacroiliitis/SI joint disruption were identified using ICD-9-CM diagnosis codes (claims with a primary or secondary ICD-9-CM diagnosis code of 71x.xx, 72x. xx, 73x.xx, or 84x.xx), and the 5-year medical resource use and Medicare reimbursement (in 2012 US dollars) were tabulated across practice settings. A subgroup analysis was performed among patients who underwent lumbar spinal fusion.

Results. Among all Medicare patients with degenerative sacroiliitis or SI joint disruption $(\mathrm{n}=14,552)$, the mean cumulative 5-year direct medical costs attributable to degenerative sacroiliitis/SI joint disruption was $\$ 18,527 \pm$ $\$ 28,285$ ( \pm SD) per patient. The cumulative 5-year cost was $\$ 63,913 \pm \$ 46,870$ per patient among the subgroup of patients who underwent lumbar spinal fusion $(\mathrm{n}=538[3.7 \%])$ and $\$ 16,769 \pm \$ 25,753$ per patient among the subgroup of patients who had not undergone lumbar spinal fusion $(n=14,014$ [96.3\%]). For the total population, the largest proportion of cumulative 5-year costs was due to inpatient hospitalization (42.1\%), outpatient physician office $(20.6 \%)$, and hospital outpatient costs $(14.9 \%)$. The estimated cumulative 5-year Medicare reimbursement across practice settings attributable to SI joint disruption or degenerative sacroiliitis is approximately $\$ 270$ million among these 14,552 Medicare beneficiaries ( $\$ 18,527$ per patient).

Conclusions. In patients who suffer from LBP due to SI joint disruption or degenerative sacroiliitis, this retrospective Medicare claims data analysis demonstrates that nonoperative care is associated with substantial costs and medical resource utilization. The economic burden of SI joint disruption and degenerative sacroiliitis among Medicare beneficiaries in the US is substantial and highlights the need for more cost-effective therapies to treat this condition and reduce health care expenditures.
\end{abstract}

(http://thejns.org/doi/abs/10.3171/2014.1.SPINE13188)

KeY Words - $\quad$ sacroiliac joint disruption $\quad \bullet \quad$ degenerative sacroiliitis epidural injection $\quad$ lumbar spinal fusion surgery $\bullet \quad$ cost

Abbreviations used in this paper: $\mathrm{CPT}=$ Current Procedural Terminology; ICD-9-CM = International Classification of Diseases, Ninth Revision, Clinical Modification; LBP = low-back pain; SAF = Standard Analytical File; SI = sacroiliac; USD = US dollars.
L ow-back pain (LBP) is an extremely prevalent condition, affecting well over $90 \%$ of adults in the US at some point during their lifetime. ${ }^{27}$ Studies have demonstrated an increase in the prevalence of chronic 
LBP over the past several decades. ${ }^{14}$ With this rising prevalence, increases in costs also have been observed. ${ }^{8}$ Low-back pain is highly prevalent in older populations, so the cost impact to the US Medicare population is substantial. In a study of the use of epidural injection rates for spinal disorders among Medicare beneficiaries, injection rates increased by $121.2 \%$, resulting in an increase in Medicare expenditures from \$396.7 million in 2002 to $\$ 743.78$ million in $2006 .{ }^{19}$ Another study examined the documentation of LBP claims among Medicare beneficiaries and these were found to have increased $131.7 \%$ from 1991 to $2002 .^{26}$

Historically, the sacroiliac (SI) joint has been considered a significant generator of LBP. However, conditions such as herniated discs and facet arthropathy, which also cause LBP, have been the focus of many of the analyses of the cost of LBP. ${ }^{28}$ More recently, published literature reported that $15 \%-30 \%$ of patients presenting with LBP had SI joint problems; this has led to a renewed focus on the SI joint as a major generator of LBP. ${ }^{24}$

Traditionally, SI joint pain treatment options have included either nonoperative care, such as physical therapy, pain management through injections, and radiofrequency ablation, or traditional open SI joint arthrodesis surgery. Nonoperative therapies address the symptoms of the condition and do not treat the underlying cause. For patients with SI joint pain that is refractory to nonoperative therapies, open SI joint arthrodesis has traditionally been the final option. Limitations of invasive, open surgery include the following: the need for large incisions, bone harvesting, joint destabilization, and longer inpatient hospital stays. Moreover, there is a high rate of postoperative complications and the patient may be non-weight bearing for several months. ${ }^{9}$

Although the clinical limitations of traditional treatment options for SI joint pain are known, the economic impact of SI joint pain treatment options has not been examined in the medical literature. Because of the lack of published economic studies to date that analyze the cost of nonoperative care for SI joint pain in a Medicare population, we evaluated the medical resource use and Medicare reimbursement for patients managed nonoperatively for degenerative sacroiliitis/SI joint disruption in a Medicare population.

\section{Methods}

\section{Study Design and Data Sources}

Medical resource use and associated Medicare reimbursement for patients with degenerative sacroiliitis/SI joint disruption were examined retrospectively for Medicare beneficiaries for a 5-year period per patient within the dates from January 1, 2005, through December 31, 2010, using the Medicare 5\% Standard Analytical Files (SAFs). The Medicare 5\% SAFs contain final action claim-level data, which can be linked across multiple years and settings of care, and represent all claims for 5\% of Medicare beneficiaries in a given year. Medicare beneficiaries remain in the SAF until they no longer receive Medicare benefits or die. The SAF data include separate files for hos- pital inpatient, hospital outpatient, physician/supplier Part $\mathrm{B}$, skilled nursing facility, home health, hospice, durable medical equipment claims, and a demographic file that indicates age, sex, date of death (if applicable), and eligibility information. Each beneficiary is assigned an encrypted identifier by the Centers for Medicare \& Medicaid Services that protects the identity of the patient but allows for researchers to track a patient from one year to the next or across different practice settings. To further protect patient confidentiality, the SAF data used for this analysis do not provide actual dates of service; rather, quarters of service are provided in the claims data. As no patient-identifying information was used in the analysis, institutional review board review or determination was not sought. This research was performed according to guidelines established to minimize conflict of interest in pharmaco-economic studies. ${ }^{11,22}$ A multispecialty panel comprising clinicians and methodologists (the coauthors) provided the framework for the economic analysis. The sponsor, SI-BONE, Inc., was invited to review the draft manuscript. All final editorial decisions were made by the coauthors.

All claims with an ICD-9-CM (International Classification of Diseases, Ninth Revision, Clinical Modification) code for degenerative sacroiliitis/SI joint disruption (diagnosis codes 720.2, 724.6, 739.4, 846.9, or 847.3) in the primary diagnosis field (Table 1) were selected from the 2005 SAF claims data; ICD-9-CM code 721.3 (lumbosacral spondylosis) was not included in the primary analysis but was added into the subsequent sensitivity analysis. Claims data from 2005 were used to identify an index diagnosis of degenerative sacroiliitis/SI joint disruption to permit 5 years of follow-up using the most current data available through 2010. Among the defined population, claims attributable to degenerative sacroiliitis/SI joint disruption were identified using ICD-9-CM diagnosis codes; specifically, claims with a primary or secondary ICD-9-CM spinal diagnosis code of 71x.xx, 72x.xx, 73x.xx, or 84x.xx were selected for analysis.

Using this method, the index quarter identified the initial quarter of degenerative sacroiliitis/SI joint disruption in 2005. Because data prior to 2005 were not examined for a degenerative sacroiliitis/SI joint disruption diagnosis, the first mention of a diagnosis in 2005 was not necessarily the first diagnosis for the patient (that is, the degenerative sacroiliitis/SI joint disruption might or might not have been newly diagnosed). Five years of data were then extracted after the index quarter to investigate medical resource use and associated reimbursement. Only patients with continuous eligibility in all 5 years were included in the analysis; this guaranteed that all patients in the analysis were alive for all 5 years, wherein they could have continued to be diagnosed and treated for SI joint-related LBP.

Because there is significant overlap of SI joint pathology and LBP requiring spinal fusion, a subgroup analysis was performed on patients with degenerative sacroiliitis/ SI joint disruption who underwent lumbar spinal fusion. Patients who underwent lumbar spinal fusion surgery were identified with ICD-9-CM procedure codes, as described in Table 2. This subgroup of patients underwent lumbar spinal fusion in either the year prior to the index 
TABLE 1: International Classification of Disease diagnosis codes used to identify degenerative sacroiliitis/SI joint disruption

\begin{tabular}{cl}
\hline ICD-9-CM Code & \multicolumn{1}{c}{ Description } \\
\hline 720.2 & sacroiliitis, not elsewhere classified, inflammation of the SI joint not otherwise specified \\
$721.3^{*}$ & lumbosacral spondylosis w/o myelopathy; lumbar or lumbosacral arthritis, osteoarthritis, or spondyloarthritis \\
724.6 & disorders of sacrum; ankylosis, lumbosacral or SI (joint); instability, lumbosacral or SI (joint) \\
739.4 & nonallopathic lesion of sacral region, not elsewhere classified \\
846.9 & sprains \& strains of SI region, unspecified site of SI region \\
847.3 & sprains \& strains of other \& unspecified parts of back; sacrum, sacrococcygeal (ligament) \\
\hline
\end{tabular}

* This code was excluded from the primary analysis and was only included in the sensitivity analysis.

diagnosis of degenerative sacroiliitis/SI joint disruption (including data from 2004 for patients with an index diagnosis in 2005) or in the subsequent 5 years. One year prior to the index diagnosis was used for identifying the subgroup of patients who underwent lumbar spinal fusion based on the clinical experience of the authors that it is common for there to be a delay in diagnosis of degenerative sacroiliitis/SI joint disruption. It is unclear how often lumbar fusion is being performed in patients who really have SI pathology, but an occurrence of at least 5\% of the time has been suggested. ${ }^{24}$ In addition, the lumbar spinal fusion subgroup analysis was conducted because lumbar spinal fusion patients with sacroiliac diagnoses may represent a group requiring greater medical resource utilization to treat than patients with the same diagnosis, but who have not had lumbar spinal fusion.

\section{Construction of Outcome Variables}

Outcomes were investigated in the index quarter and the subsequent 5 years. Degenerative sacroiliitis/SI joint disruption-attributable costs were defined as claims with any of the following ICD-9-CM diagnosis codes in any diagnosis field: $71 \mathrm{x} . \mathrm{xx}-73 \mathrm{x} . \mathrm{xx}$ (disease of the musculoskeletal system and connective tissue, excluding 721.3) or 84x.xx (sprains and strains of joints and adjacent muscles). Medical resource use and associated Medicare reimburse- ment were identified and evaluated for each subsequent year following the initial degenerative sacroiliitis/SI joint disruption diagnosis. Medical resource use was identified using Current Procedural Terminology (CPT) codes that describe surgical procedures, hospital inpatient, hospital outpatient, physician office, and emergency department visits as well as other diagnostic tests and procedures including, but not limited to, physical therapy, chiropractic manipulation, prolotherapy, therapeutic injection (SI joint), trigger point injection, epidural steroid injection/ selective nerve root block, facet block, pelvic radiography, and MRI/CT examinations. Total 5-year cumulative Medicare reimbursement (not including patient or supplemental plan contribution) was identified for each of these settings and for each medical resource and is reported in 2012 US dollars (USD). Dollar amounts were converted to 2012 USD using the semiannual average from the first half of 2012 from the medical care component of the Consumer Price Index (Bureau of Labor Statistics, Table 31, http://www.bls.gov/cpi/cpid09fv.pdf).

\section{Statistical Analysis}

Analyses were performed for all patients with a diagnosis of degenerative sacroiliitis/SI joint disruption and for 2 subgroups, those with and those without lumbar spinal fusion surgery. Descriptive statistics were calculated on

TABLE 2: International Classification of Disease procedure codes used to identify patients who underwent lumbar spinal fusion surgery*

\begin{tabular}{cl}
\hline ICD-9-CM Code & \multicolumn{1}{c}{ Description } \\
\hline 81.05 & dorsal \& dorsolumbar fusion, posterior technique \\
81.06 & lumbar \& lumbosacral fusion, anterior technique \\
81.07 & lumbar \& lumbosacral fusion, lateral transverse process technique \\
81.08 & lumbar \& lumbosacral fusion, posterior technique \\
81.35 & refusion of dorsal \& dorsolumbar spine, posterior technique \\
81.36 & refusion of lumbar \& lumbosacral spine, anterior technique \\
81.37 & refusion of lumbar \& lumbosacral spine, lateral transverse process technique \\
81.38 & refusion of lumbar \& lumbosacral spine, posterior technique \\
81.62 & fusion or refusion of 2-3 vertebrae \\
81.63 & fusion or refusion of 4-8 vertebrae \\
81.64 & fusion or refusion of $\geq 9$ vertebrae \\
\hline * The following code algorithms were used: (81.62 AND [81.05 OR 81.06 OR 81.07 OR 81.08 OR 81.35 OR 81.36 OR 81.37 OR \\
81.38]) or ([81.62 OR 81.63 OR 81.64] AND [81.05 OR 81.07 OR 81.35 OR 81.37]).
\end{tabular}


demographic characteristics and primary diagnoses during the index quarter based on the initial index claim with a primary diagnosis of sacroiliitis, disorders of sacrum, SI subluxation, sprain/strain in SI region, or sprain/strain of sacrum. Direct medical resource utilization and costs attributable to SI joint disruption were analyzed cumulatively over 5 years following initial diagnosis and across settings of care, including hospital inpatient, hospital outpatient, physician office, and emergency department. All statistical analyses were performed using SAS software (version 9.1.3, SAS Institute, Inc.).

\section{Results}

Demographics and Primary Diagnoses of Overall Study Sample and Subgroups

The Medicare SAF analysis identified 14,552 patients with degenerative sacroiliitis or SI joint disruption with continuous enrollment for at least 1 year before and 5 years after diagnosis (Table 3). Of these, 538 (3.7\%) had lumbar spinal fusion surgery. The mean age of the overall Medicare population was 69.5 years, and $82.4 \%$ of patients were 65 years or older (Table 4 ). In the overall population, the most common primary diagnoses were SI subluxation (48.8\%), sacroiliitis (23.3\%), and disorders of the sacrum $(20.3 \%)$. In the spinal fusion subgroup, $42.8 \%$ of patients had a primary diagnosis of disorders of the sacrum, while $24.5 \%$ were diagnosed with SI subluxation.

\section{Medical Resource Utilization in the Overall Study Sample and Subgroups}

The cumulative medical resource use over 5 years is presented in Table 5. Among the $41.2 \%$ of patients with a hospitalization, there was an average of 2.0 hospital inpatient stays over 5 years. Overall, patients had an average of 48.7 outpatient physician office visits over the 5-year follow-up period. Physical therapy (mean 15.9 claims for the $59.3 \%$ using a physical therapist) and chiropractic manipulation (mean 30.0 claims for the $61.3 \%$ using a chiropractor) also were used by patients with degenerative sacroiliitis/SI joint disruption over the 5-year follow-up period. A larger percentage of lumbar spinal fusion surgery patients used medical resources (for example, hospitalizations, hospital outpatient visits, emergency department visits, physical therapy, prolotherapy, therapeutic SI joint injections, epidural steroid injections, facet blocks, pelvic radiography, and CT/MRI examinations), compared with those without lumbar spinal fusion surgery.

\section{Cost of Nonoperative Care in the Overall Study Sample and Subgroups}

Nonoperative care represents a resource-intense process, including, but not limited to, hospitalizations, clinic visits, therapeutic manual interventions (for example, physical therapy and chiropractic manipulation), medications, injections, and imaging, which add up to substantial costs. The cumulative 5-year direct medical costs (2012 USD) attributable to degenerative sacroiliitis/SI joint disruption were $\$ 18,527 \pm \$ 28,285( \pm \mathrm{SD})$ per patient for all patients. Costs were $\$ 63,913 \pm \$ 46,870$ per patient for lumbar spinal fusion patients and $\$ 16,769 \pm \$ 25,753$ per patient for patients without lumbar spinal fusion (Table 6). Cumulative costs increased linearly over time (Fig. 1). For all patients, the cumulative costs increased from $\$ 4583$ in Year 1 to $\$ 18,527$ in Year 5. For lumbar spinal fusion patients, cumulative costs increased from $\$ 19,021$ in Year 1 to $\$ 63,913$ in Year 5. For patients without lumbar spinal fusion, the cumulative costs increased from $\$ 4018$ in Year 1 to $\$ 16,769$ in Year 5.

The largest proportion of cumulative 5-year costs was due to inpatient hospitalization $(42.1 \%$ for all patients, $67.1 \%$ for the lumbar spinal fusion subgroup, and $38.5 \%$ for the subgroup without lumbar spinal fusion). Following hospitalization, outpatient physician office costs composed the second largest proportion of costs, ranging from $10.7 \%$ for the lumbar spinal fusion subgroup to $22.1 \%$ for the subgroup without lumbar spinal fusion.

\section{Sensitivity Analysis (Inclusion of ICD-9-CM Code 721.3)}

The ICD-9-CM code 721.3, described as "lumbosacral spondylosis without myelopathy, lumbar or lumbosacral: arthritis, osteoarthritis, or spondyloarthritis," may also include patients with SI joint disruption and degenerative sacroiliitis. To understand how inclusion of this code affects medical resource utilization and costs, a sensitivity analysis was performed using patients with ICD9-CM code 721.3 in the primary diagnosis field. With the exclusion of ICD-9-CM code 721.3, a total of 14,552 patients with degenerative sacroiliitis or SI joint disruption were identified in the Medicare SAF database, whereas with the inclusion of ICD-9-CM code 721.3, a total of 35,464 patients with degenerative sacroiliitis or SI joint disruption were identified $(20,912$ with a primary diagnosis code of 721.3). Of these 35,464 patients, 1901 (5.4\%) had lumbar spinal fusion surgery and 33,563 (94.6\%) did not have lumbar spinal fusion (Table 7). With ICD-9-CM code 721.3 included, the cumulative 5-year mean overall

\section{TABLE 3: Patient attrition}

\begin{tabular}{lc}
\hline \multicolumn{1}{c}{ Criterion } & No. of Patients \\
\hline patients w/ claims in 2005-2010 & $3,022,180$ \\
patients w/ diagnosis of degenerative sacroiliitis/SI joint disruption* & 20,414 \\
patients continuously enrolled for $\geq 1$ yr before \& 5 yrs after index date $†$ & 14,552 \\
\hline
\end{tabular}

\footnotetext{
* Defined as ICD-9-CM diagnosis codes 720.2, 724.6, 739.4, 846.9, or 847.3, in the primary diagnosis field.

$\dagger$ The index date is defined as the calendar quarter of the earliest claim with a primary diagnosis code for degenerative sacroiliitis/ Sl joint disruption.
} 
TABLE 4: Demographics and primary diagnosis of patients with degenerative sacroiliitis/SI joint disruption*

\begin{tabular}{|c|c|c|c|}
\hline Parameter & Overall $(n=14,552)$ & $\begin{array}{l}\text { Patients w/ Lumbar Spinal } \\
\text { Fusion }(n=538)\end{array}$ & $\begin{array}{l}\text { Patients w/o Lumbar Spinal } \\
\text { Fusion }(n=14,014)\end{array}$ \\
\hline \multicolumn{4}{|l|}{ age } \\
\hline mean \pm SD & $69.5 \pm 10.9$ & $65.9 \pm 11.2$ & $69.6 \pm 10.9$ \\
\hline median (range) & $71.0(21.0-97.0)$ & $69.0(23.0-87.0)$ & $71.0(21.0-97.0)$ \\
\hline \multicolumn{4}{|l|}{ age group } \\
\hline$<65$ & $2564(17.6)$ & $163(30.3)$ & 2401 (17.1) \\
\hline$\geq 65$ & $11,988(82.4)$ & $375(69.7)$ & $11,613(82.9)$ \\
\hline \multicolumn{4}{|l|}{ race } \\
\hline white & $13,564(93.2)$ & $487(90.5)$ & $13,077(93.3)$ \\
\hline black & $577(4.0)$ & $40(7.4)$ & $537(3.8)$ \\
\hline Asian & $99(0.7)$ & $1(0.2)$ & $98(0.7)$ \\
\hline Hispanic & $160(1.1)$ & $3(0.6)$ & $157(1.1)$ \\
\hline other race & $152(1.0)$ & $7(1.3)$ & $145(1.0)$ \\
\hline \multicolumn{4}{|l|}{ sex } \\
\hline male & $4775(32.8)$ & $162(30.1)$ & $4613(32.9)$ \\
\hline female & 9777 (67.2) & $376(69.9)$ & $9401(67.1)$ \\
\hline \multicolumn{4}{|l|}{ primary diagnosis } \\
\hline sacroiliitis $\dagger$ & $3385(23.3)$ & $156(29.0)$ & $3229(23.0)$ \\
\hline disorders of sacrum $\ddagger$ & $2959(20.3)$ & $230(42.8)$ & $2729(19.5)$ \\
\hline SI subluxation§ & 7107 (48.8) & $132(24.5)$ & $6975(49.8)$ \\
\hline sprain/strain in SI region & $923(6.3)$ & $18(3.3)$ & $905(6.5)$ \\
\hline sprain/strain of sacrum ${ }^{* *}$ & $178(1.2)$ & $2(0.4)$ & $176(1.3)$ \\
\hline \multicolumn{4}{|c|}{$\begin{array}{l}\text { * Degenerative sacroiliitis/SI joint disruption is defined as ICD-9 } \\
\text { primary diagnosis field. Values are presented as the number of } \\
\text { as SD and median values are presented as the median (range). } \\
\text { † Defined as primary diagnosis code } 720.2 \text {. } \\
\text { † Defined as primary diagnosis code } 724.6 \text {. } \\
\S \text { Defined as primary diagnosis code } 739.4 \text {. } \\
\text { ๆ Defined as primary diagnosis code } 846.9 \text {. } \\
\text { ** Defined as primary diagnosis code } 847.3\end{array}$} \\
\hline
\end{tabular}

costs of $\$ 23,149$ per patient were higher than when ICD9-CM code 721.3 was excluded (\$18,527 per patient). Costs for patients without lumbar spinal fusion were higher than in the original analysis $(\$ 20,856$ vs $\$ 16,769$ per patient), whereas costs for patients with lumbar spinal fusion were similar to the original analysis $(\$ 63,412$ vs $\$ 63,913$; Table 7$)$. The distribution of costs across settings of care was similar to the original analysis.

\section{Discussion}

To our knowledge, this study is the first to evaluate the Medicare cost of nonoperative care in treating SI joint disruption and degenerative sacroiliitis in the Medicare population. The analysis found that cumulative 5-year mean costs for Medicare patients with degenerative sacroiliitis or SI joint disruption were $\$ 18,527$ per patient overall, $\$ 63,913$ per patient among patients with lumbar spinal fusion, and $\$ 16,769$ per patient among patients without lumbar spinal fusion. The largest proportion of cumulative 5-year costs in the overall population was due to inpatient hospitalization $(42.1 \%)$ and outpatient physi- cian office visits $(20.6 \%)$. Costs were even greater when patients diagnosed with ICD-9-CM code 721.3 (lumbosacral spondylosis) were included in the analysis.

This study demonstrates that costs associated with nonoperative care and management of Medicare patients with SI joint pain steadily increased over a 5-year followup period. The estimated national medical expenditure (Medicare payments) over 5 years across practice settings attributable to SI joint disruption and degenerative sacroiliitis is approximately $\$ 270$ million among these 14,552 Medicare beneficiaries with a diagnosis of SI joint disruption $(\$ 18,527$ per patient); this estimate increases to $\$ 821$ million when ICD-9-CM code 721.3 is included (35,464 beneficiaries at $\$ 23,149$ per patient). If we were to extrapolate to the estimated 291,040 (excluding ICD-9-CM code 721.3) to 709,280 (including ICD-9-CM code 721.3) Medicare beneficiaries with a diagnosis of SI joint disruption, the estimated national medical expenditure across practice settings attributable to SI joint disruption is approximately $\$ 15.0$ billion to $\$ 43.2$ billion over Medicare patients' lifetimes (S Ackerman et al., abstract presented at the 8th Interdisciplinary World Congress on Low Back \& Pelvic Pain, 
Cost of nonoperative care in SI joint disruption

TABLE 5: Cumulative 5-year degenerative sacroiliitis/SI joint disruption attributable to direct medical resource utilization per patient*

\begin{tabular}{|c|c|c|c|}
\hline & Overall $(n=14,552)$ & $\begin{array}{l}\text { Patients w/ Lumbar Spinal } \\
\text { Fusion }(n=538)\end{array}$ & $\begin{array}{l}\text { Patients w/o Lumbar Spinal } \\
\text { Fusion }(n=14,014)\end{array}$ \\
\hline \multicolumn{4}{|l|}{ hospitalizations } \\
\hline no. $(\%)$ & 5999 (41.2) & $500(92.9) \dagger$ & 5499 (39.2) \\
\hline mean $\pm S D$ & $2.0 \pm 1.7$ & $2.7 \pm 2.2$ & $2.0 \pm 1.6$ \\
\hline \multicolumn{4}{|c|}{ hospital outpatient visits } \\
\hline no. $(\%)$ & $11,955(82.2)$ & $528(98.1)$ & $11,427(81.5)$ \\
\hline mean $\pm \mathrm{SD}$ & $9.5 \pm 12.9$ & $15.5 \pm 15.3$ & $9.3 \pm 12.7$ \\
\hline \multicolumn{4}{|c|}{ outpatient physician office visits } \\
\hline no. $(\%)$ & $14,408(99.0)$ & $538(100.0)$ & $13,870(99.0)$ \\
\hline mean \pm SD & $48.7 \pm 49.3$ & $67.6 \pm 66.9$ & $48.0 \pm 48.4$ \\
\hline \multicolumn{4}{|c|}{ emergency department visits } \\
\hline no. $(\%)$ & $4923(33.8)$ & $252(46.8)$ & $4671(33.3)$ \\
\hline mean $\pm S D$ & $3.8 \pm 10.0$ & $5.9 \pm 10.8$ & $3.7 \pm 9.9$ \\
\hline \multicolumn{4}{|c|}{ physical therapy claims $\ddagger$} \\
\hline no. $(\%)$ & $8634(59.3)$ & $443(82.3)$ & $8191(58.4)$ \\
\hline mean $\pm S D$ & $15.9 \pm 27.6$ & $18.7 \pm 33.6$ & $15.7 \pm 27.2$ \\
\hline \multicolumn{4}{|c|}{ chiropractic manipulation claims§ } \\
\hline no. $(\%)$ & $8926(61.3)$ & $228(42.4)$ & 8698 (62.1) \\
\hline mean \pm SD & $30.0 \pm 36.7$ & $26.8 \pm 54.0$ & $30.1 \pm 36.1$ \\
\hline \multicolumn{4}{|c|}{ 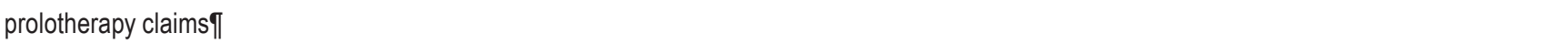 } \\
\hline no. $(\%)$ & $4524(31.1)$ & $280(52.0)$ & $4244(30.3)$ \\
\hline mean \pm SD & $4.0 \pm 5.6$ & $4.4 \pm 4.5$ & $4.0 \pm 5.7$ \\
\hline \multicolumn{4}{|c|}{ therapeutic injection claims (SI joint) ${ }^{* *}$} \\
\hline no. $(\%)$ & $2659(18.3)$ & $212(39.4)$ & $2447(17.5)$ \\
\hline mean $\pm S D$ & $3.1 \pm 3.7$ & $3.2 \pm 3.1$ & $3.1 \pm 3.8$ \\
\hline \multicolumn{4}{|c|}{ trigger point injection claims $† \dagger$} \\
\hline no. $(\%)$ & $1698(11.7)$ & $122(22.7)$ & $1576(11.2)$ \\
\hline mean \pm SD & $4.1 \pm 6.9$ & $3.4 \pm 5.8$ & $4.2 \pm 7.0$ \\
\hline \multicolumn{4}{|c|}{ epidural steroid injection/selective nerve root block claimsł‡ } \\
\hline no. $(\%)$ & $4066(27.9)$ & $346(64.3)$ & $3720(26.5)$ \\
\hline mean $\pm S D$ & $6.9 \pm 7.2$ & $7.6 \pm 6.6$ & $6.8 \pm 7.3$ \\
\hline \multicolumn{4}{|c|}{ facet block claims§§ } \\
\hline no. $(\%)$ & $1890(13.0)$ & $157(29.2)$ & $1733(12.4)$ \\
\hline mean \pm SD & $4.4 \pm 5.3$ & $3.5 \pm 3.0$ & $4.4 \pm 5.5$ \\
\hline \multicolumn{4}{|c|}{ pelvic x-ray claims $\| \Uparrow$} \\
\hline no. $(\%)$ & 5706 (39.2) & $312(58.0)$ & $5394(38.5)$ \\
\hline mean $\pm S D$ & $2.8 \pm 2.4$ & $3.0 \pm 3.0$ & $2.7 \pm 2.4$ \\
\hline \multicolumn{4}{|c|}{ MR/CT exam claims ${ }^{\text {aa }}$} \\
\hline no. $(\%)$ & $7111(48.9)$ & $499(92.8)$ & $6612(47.2)$ \\
\hline mean $\pm S D$ & $3.2 \pm 2.6$ & $5.4 \pm 4.1$ & $3.0 \pm 2.4$ \\
\hline
\end{tabular}

* Degenerative sacroiliitis/SI joint disruption attributable to direct medical resource utilization defined as claims with an ICD-9-CM diagnosis code of 71x.xx, 72x.xx, 73x.xx, or 84x.xx in any diagnosis field. The mean numbers of claims were calculated only among patients with at least 1 claim.

$\dagger$ Does not include lumbar spinal surgery performed prior to the index date, that is, prior to receiving a diagnosis of SI joint dysfunction.

$\ddagger$ Physical therapy claims are identified using CPT codes 90901, 95831, 95851, 95852, 97001, 97002, 97010, 97032, 97110, 97112, 97116, 97124, $97140,97150,97530$, and 97535 .

$\S$ Chiropractic manipulation claims are identified using CPT codes 98940-98943.

II Prolotherapy claims are identified using CPT codes M0076, 20550-20552, 20999, and 27096.

** Therapeutic injection claims for the SI joint are identified using CPT code 27096.

†† Trigger point injection claims are identified using CPT codes 20552 and 20553.

(continued) 
TABLE 5: Cumulative 5-year degenerative sacroiliitis/SI joint disruption attributable to direct medical resource utilization per patient* (continued)

掞pidural steroid injection/selective nerve root block claims are identified using CPT codes 62310, 62311, 64479, 64484, and 77003.

$\S \S$ Facet block claims are identified using CPT codes 64490-64495.

IT Pelvic x-ray claims are identified using CPT codes 72170, 73500, 73510, and 73520.

aa MR/CT exam claims are identified using CPT codes 72131-72133, 72141, 72142, 72146-72149, 72156, 72158, 72159, 72190, 72192-72198, 72202,

$72220,72265,72270,73525,73542$, and 73550 .

Dubai, United Arab Emirates, 2013). This extrapolation assumes that the calculated 5-year costs apply to all Medicare patients with a diagnosis of degenerative sacroiliitis/SI joint disruption. As reflected in Table 3, among patients with a diagnosis of degenerative sacroiliitis/SI joint disruption in the Medicare SAFs, $71.3 \%(14,552$ of 20,414$)$ were continuously enrolled for at least 1 year before and 5 years after the index diagnosis when ICD-9-CM code 721.3 was excluded (73.3\% [35,464 of 48,403] when ICD-9-CM code 721.3 was included). For the remaining 27\%-29\% of patients without continuous enrollment (who died, unenrolled, or lost Medicare coverage during the 5-year follow-up period), we have made the extrapolation assumption that the same 5-year costs would apply. We can only speculate about whether, on average, the actual "unobserved" 5-year costs in this 27\%$29 \%$ of patients would be similar, higher, or lower than those Medicare beneficiaries with continuous enrollment. Note that if we conservatively estimated national medical expenditures using only the $71.3 \%-73.3 \%$ of patients with 5-year costs in the Medicare SAFs, then the estimated national medical expenditures attributable to SI joint disruption is approximately $\$ 10.7$ billion (when ICD-9-CM code 721.3 is excluded) to $\$ 31.7$ billion (when ICD-9-CM code 721.3 is included) over Medicare patients' lifetimes.

As a point of reference, the annual economic burden per patient of SI joint disruption is approximately half that of heart failure and several times more than hypertension. Specifically, the annual costs of heart failure have been estimated at $\$ 8500$ per patient, ${ }^{4}$ whereas the annual costs of hypertension have been estimated at $\$ 1131$ per patient. ${ }^{3}$

Within this analysis, a subgroup of patients who underwent lumbar spinal fusion surgery (3.7\% of patients)

TABLE 6: Cumulative 5-year degenerative sacroiliitis/SI joint disruption-attributable direct medical costs per patient*

\begin{tabular}{|c|c|c|c|}
\hline Parameter & Overall $(n=14,552)$ & $\begin{array}{l}\text { Patients w/ Lumbar Spinal } \\
\text { Fusion }(n=538)\end{array}$ & $\begin{array}{l}\text { Patients w/o Lumbar Spina } \\
\text { Fusion }(n=14,014)\end{array}$ \\
\hline \multicolumn{4}{|l|}{ total costs $\dagger$} \\
\hline mean $\pm S D$ & $\$ 18,527 \pm 28,285$ & $\$ 63,913 \pm 46,870$ & $\$ 16,769 \pm 25,753$ \\
\hline median & $\$ 7376$ & $\$ 54,564$ & $\$ 6789$ \\
\hline \multicolumn{4}{|l|}{ hospitalization costs } \\
\hline mean \pm SD & $\$ 19,071 \pm 23,191$ & $\$ 46,263 \pm 35,267$ & $\$ 16,584 \pm 19,900$ \\
\hline median & $\$ 12,894$ & $\$ 38,549$ & $\$ 11,885$ \\
\hline$\%$ total cost & 42.1 & 67.1 & 38.5 \\
\hline \multicolumn{4}{|l|}{ hospital outpatient costs } \\
\hline mean $\pm S D$ & $\$ 3370 \pm 5401$ & $\$ 6166 \pm 7149$ & $\$ 3240 \pm 5270$ \\
\hline median & $\$ 1545$ & $\$ 4198$ & $\$ 1472$ \\
\hline$\%$ total cost & 14.9 & 9.4 & 15.7 \\
\hline \multicolumn{4}{|c|}{ outpatient physician office costs } \\
\hline mean $\pm S D$ & $\$ 3897 \pm 6210$ & $\$ 6894 \pm 11,075$ & $\$ 3780 \pm 5910$ \\
\hline median & $\$ 2200$ & $\$ 4893$ & $\$ 2122$ \\
\hline$\%$ total cost & 20.6 & 10.7 & 22.1 \\
\hline \multicolumn{4}{|c|}{ emergency department costs } \\
\hline mean $\pm S D$ & $\$ 225 \pm 549$ & $\$ 373 \pm 746$ & $\$ 216 \pm 533$ \\
\hline median & $\$ 123$ & $\$ 152$ & $\$ 122$ \\
\hline$\%$ total cost & 0.4 & 0.3 & 0.4 \\
\hline
\end{tabular}

* Degenerative sacroiliitis/SI joint disruption-attributable costs are defined as claims with an ICD-9-CM diagnosis code of 71x.XX, 72x.xx,73x.xx, or 84x.xx in any diagnosis field. Mean costs are calculated only among patients with non-zero costs. All costs were inflated to 2012 USD using the semiannual average from the first half of 2012 of the medical care component of the Consumer Price Index. Costs reported as $\$ 0$ are due to rounding, as values $<\$ 0.50$ were rounded down to $\$ 0$.

$\dagger$ Total costs are defined as the sum of hospitalization, hospital outpatient, physician office, emergency department, and other facility costs (e.g., skilled nursing facility, hospice, home health, durable medical equipment, ambulatory surgery center, ambulance, independent laboratory, or nursing home costs). 


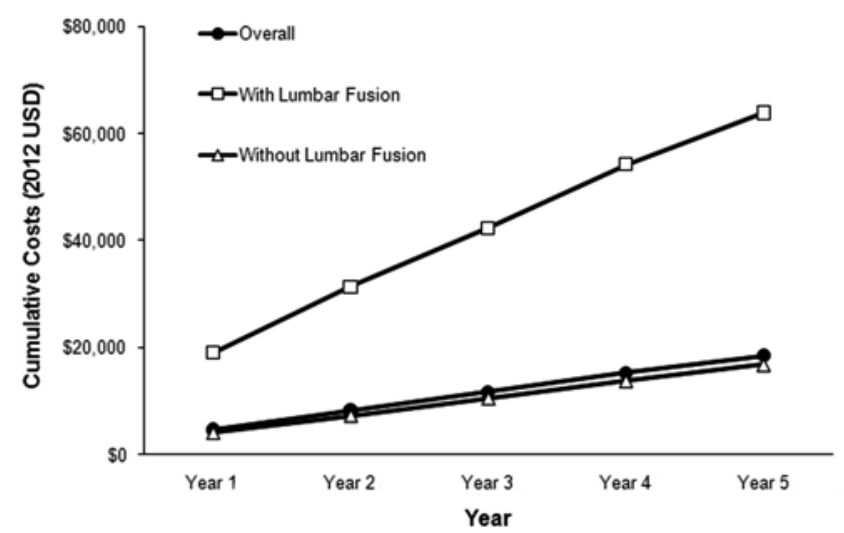

FIG. 1. Cumulative direct medical costs per patient over the 5-year period (2012 USD). Each dot symbolizes the mean cost for the claims occurring in the year(s) subsequent to the earliest claim with a primary diagnosis of degenerative sacroiliitis/SI joint disruption (defined as ICD9-CM diagnosis codes $720.2,724.6,739.4,846.9$, or 847.3 ).

incurred substantial economic burden (over 3-fold the per-patient 5-year cumulative costs $[\$ 63,913]$ compared with patients without lumbar spinal fusion surgery $[\$ 16,769])$. The higher cost of patients undergoing lumbar spinal fusion is a concern, given that the rate of lumbar spinal fusion surgery has increased 3-fold from 1998 to 2008, whereas laminectomy increased only $11 \%$ during that time period. ${ }^{12}$ The mean total hospital charges for lumbar spinal fusions increased 3.3-fold during the same time period based on an analysis of the Healthcare Cost and Utilization Project Nationwide Inpatient Sample, which is an all-payer database containing data from $20 \%$ of community hospitals in the US. ${ }^{21}$ Not only is lumbar spinal fusion surgery more expensive and, at times, does not ameliorate symptoms, ${ }^{1,13,15}$ patients treated with lumbar spinal fusion are more likely to develop subsequent SI joint degeneration. In a prospective study of 32 patients who received decompression and instrumented posterolateral lumbar/lumbosacral fusion, SI joint degeneration developed more frequently in patients with lumbar spinal fusion (75.0\%) than controls $(38.2 \%),{ }^{12}$ which suggests a potential increase in future costs associated with SI joint degeneration due to the increasing numbers of patients undergoing lumbar spinal fusion.

\section{Limitations}

There are several limitations to this Medicare SAF claims data analysis. First, SI joint dysfunction is often misdiagnosed or miscoded. Because we lack a gold standard for SI joint pain diagnosis, ${ }^{5,17,18,25}$ a multispecialty panel of

TABLE 7: Sensitivity analysis of cumulative 5-year degenerative sacroiliitis/SI joint disruption-attributable direct medical costs per patient including ICD-9-CM code 721.3*

\begin{tabular}{|c|c|c|c|}
\hline Parameter & Overall $(n=35,464)$ & $\begin{array}{l}\text { Patients w/ Lumbar Spinal } \\
\text { Fusion }(n=1901)\end{array}$ & $\begin{array}{l}\text { Patients w/o Lumbar Spinal } \\
\text { Fusion }(n=33,563)\end{array}$ \\
\hline \multicolumn{4}{|l|}{ total costs $†$} \\
\hline mean $\pm S D$ & $\$ 23,149 \pm 31,739$ & $\$ 63,412 \pm 45,881$ & $\$ 20,856 \pm 29,110$ \\
\hline median & $\$ 11,214$ & $\$ 53,351$ & $\$ 10,072$ \\
\hline \multicolumn{4}{|l|}{ hospitalization costs } \\
\hline mean $\pm S D$ & $\$ 20,420 \pm 23,814$ & $\$ 45,355 \pm 32,237$ & $\$ 17,571 \pm 20,835$ \\
\hline median & $\$ 13,499$ & $\$ 37,871$ & $\$ 12,143$ \\
\hline$\%$ total cost & 43.5 & 67.4 & 39.4 \\
\hline \multicolumn{4}{|c|}{ hospital outpatient costs } \\
\hline mean $\pm S D$ & $\$ 3813 \pm 5933$ & $\$ 5966 \pm 7253$ & $\$ 3676 \pm 5790$ \\
\hline median & $\$ 1886$ & $\$ 3788$ & $\$ 1805$ \\
\hline$\%$ total cost & 14.4 & 9.2 & 15.3 \\
\hline \multicolumn{4}{|c|}{ outpatient physician office costs } \\
\hline mean $\pm S D$ & $\$ 4313 \pm 6838$ & $\$ 6668 \pm 10,176$ & $\$ 4177 \pm 6568$ \\
\hline median & $\$ 2497$ & $\$ 4437$ & $\$ 2402$ \\
\hline$\%$ total cost & 18.2 & 10.5 & 19.5 \\
\hline \multicolumn{4}{|c|}{ emergency department costs } \\
\hline mean $\pm S D$ & $\$ 220 \pm 440$ & $\$ 301 \pm 579$ & $\$ 215 \pm 429$ \\
\hline median & $\$ 131$ & $\$ 148$ & $\$ 130$ \\
\hline$\%$ total cost & 0.4 & 0.2 & 0.4 \\
\hline
\end{tabular}

\footnotetext{
* Degenerative sacroilitis/SI joint disruption-attributable costs are defined as claims with an ICD-9-CM diagnosis code of 71x. $x x, 72 x . x x, 73 x . x x$, or 84x.xx in any diagnosis field. Mean costs are calculated only among patients with non-zero costs. All costs were inflated to 2012 USD using the semiannual average from the first half of 2012 of the medical care component of the Consumer Price Index. Costs reported as $\$ 0$ are due to rounding, as values $<\$ 0.50$ were rounded down to $\$ 0$.

$\dagger$ Total costs are defined as the sum of hospitalization, hospital outpatient, physician office, emergency department, and other facility costs (e.g., skilled nursing facility, hospice, home health, durable medical equipment, ambulatory surgery center, ambulance, independent laboratory, or nursing home costs).
} 
clinicians and methodologists informed the development of an algorithm to identify the patient cohort for the claims data analysis. Given that our study is based on Medicare claims that are dependent on the coding entered by the treating clinician at the time of the encounter, the methodology is imperfect; yet it is a well-accepted approach in burden of disease research ${ }^{23}$ and allows policy makers to allocate resources based on relative burden of disease. A similar methodology has been used to estimate the economic burden of illness for cardiovascular disease ${ }^{6,16}$ and diabetes, ${ }^{2}$ as well as LBP. ${ }^{10,19,20}$ As with any retrospective claims analysis, the reliance on a coding system to identify patients with a clinical condition may lead to a lack of sensitivity and specificity. To increase the specificity of the cohort identification, only patients with an ICD-9-CM code for degenerative sacroiliitis/SI joint disruption in the primary diagnosis position were selected. This approach, while less sensitive, allowed us more certainty that the patient was seeking care for the SI joint, rather than another condition. Furthermore, to increase the specificity of the claims identification, only those claims attributable to degenerative sacroiliitis/SI joint disruption were selected for analysis, that is, claims with a primary or secondary ICD9-CM spinal diagnosis code of 71x.xx, 72x.xx, 73x.xx, or $84 x . x x$. Because it is not known for certain whether the medical resources reflected on such claims were incurred specifically for SI joint disruption, it is possible that the costs associated with treatment of SI joint disruption may have been overestimated. Nevertheless, an exploratory analysis demonstrated that $75 \%$ of physician office visit costs were from spinal claims with a relevant provider specialty (for example, orthopedic surgery or neurosurgery rather than primary care), which gives us confidence that most costs were SI joint related and not due to other conditions such as hypertension. In addition, due to some ambiguity and heterogeneity in the assignment of ICD-9-CM code 721.3 (lumbosacral spondylosis), we performed a sensitivity analysis by including this code, which resulted in more than doubling the population size (from 14,552 to 35,464 patients) and a $25 \%$ increase in 5-year cumulative costs (from $\$ 18,527$ to $\$ 23,148$ per patient overall).

Another important limitation of the Medicare SAFs is the lack of retail pharmacy claims data. Because patients treated with nonoperative care will likely be treated with opioids and other prescription pain medications, the lack of these data resulted in underestimating the costs of managing SI joint disruption among Medicare beneficiaries. In addition, the inclusion criterion requiring 5 years of continuous enrollment could have led to selection of a healthier, elderly population; therefore, this approach also may have led to underestimating the costs of nonoperative care for degenerative sacroiliitis/SI joint disruption. Furthermore, the per-patient costs for patients who underwent lumbar spinal fusion do not include lumbar spinal fusion performed in the year prior to receiving a diagnosis of SI joint disruption. The assignment of an SI joint disruption diagnosis up to a year after a patient underwent lumbar spinal fusion could represent new disease or an earlier misdiagnosis; therefore, these costs were not included in the present analysis, which may have resulted in underestimating the costs. Of note, a recent study found that among patients experiencing LBP who underwent lumbar spinal fusion, the most likely source (in 12 of 28 patients [43\%]) was SI joint pain as opposed to internal disc disruption, zygapophysial joint pain, or soft-tissue irritation from fusion hardware. ${ }^{7}$ In the same study, only $13 \%$ of patients without fusion experienced SI joint pain. Lastly, dates of service are available only in terms of quarters in the database, so it was not possible to determine the order of events when both occurred in the same quarter. As a result, because we could not determine whether medical resources from the quarter in which the patient received a diagnosis of SI joint disruption or degenerative sacroiliitis occurred prior to or following diagnosis, we included all spine-related medical resources from that quarter.

\section{Conclusions}

Recent US health care reform legislation focuses on improving quality of care and reducing costs. In patients who suffer from LBP due to SI joint disruption or degenerative sacroiliitis, this retrospective Medicare claims data analysis demonstrates that nonoperative care is associated with substantial costs and high levels of medical resource utilization. The economic burden of SI joint disruption and degenerative sacroiliitis among Medicare beneficiaries in the US is substantial and highlights the need for more cost-effective therapies to treat this condition and reduce health care expenditures.

\section{Acknowledgment}

We thank Karen Spach, Ph.D., of Covance Market Access Services Inc., for her editorial contribution to this paper.

\section{Disclosure}

This study was sponsored by SI-BONE, Inc. Authors S.J.A. and T.K. are consultants to SI-BONE through their employment at Covance. Author D.W.P. receives research support from the Department of Defense, Orthopaedic Research and Education Foundation, Minnesota Medical Foundation, and Chest Wall and Spine Deformity Foundation. Authors T.H. and J.C. are paid research and teaching consultants for SI-BONE. J.C. is also a consultant for $\mathrm{NuVasive.}$

Author contributions to the study and manuscript preparation include the following. Conception and design: Ackerman, Polly, Holt, Cummings. Acquisition of data: Knight. Analysis and interpretation of data: Ackerman, Polly, Knight. Drafting the article: Ackerman. Critically revising the article: all authors. Reviewed submitted version of manuscript: all authors. Approved the final version of the manuscript on behalf of all authors: Ackerman. Statistical analysis: Knight.

\section{References}

1. Airaksinen O, Herno A, Turunen V, Saari T, Suomlainen O: Surgical outcome of 438 patients treated surgically for lumbar spinal stenosis. Spine (Phila Pa 1976) 22:2278-2282, 1997

2. American Diabetes Association: Economic costs of diabetes in the U.S. in 2012. Diabetes Care 36:1033-1046, 2013

3. Balu S, Thomas J III: Incremental expenditure of treating hypertension in the United States. Am J Hypertens 19:810-817, 2006

4. Braunschweig F, Cowie MR, Auricchio A: What are the costs of heart failure? Europace 13 (Suppl 2):ii13-ii17, 2011 
5. Chou R, Loeser JD, Owens DK, Rosenquist RW, Atlas SJ, Baisden J, et al: Interventional therapies, surgery, and interdisciplinary rehabilitation for low back pain: an evidence-based clinical practice guideline from the American Pain Society. Spine (Phila Pa 1976) 34:1066-1077, 2009

6. Copher R, Cerulli A, Watkins A, Monsalvo ML: Treatment patterns and healthcare system burden of managed care patients with suspected pulmonary arterial hypertension in the United States. J Media Econ 15:947-955, 2012

7. DePalma MJ, Ketchum JM, Saullo TR: Etiology of chronic low back pain in patients having undergone lumbar fusion. Pain Med 12:732-739, 2011

8. Freburger JK, Holmes GM, Agans RP, Jackman AM, Darter JD, Wallace AS, et al: The rising prevalence of chronic low back pain. Arch Intern Med 169:251-258, 2009

9. Giannikas KA, Khan AM, Karski MT, Maxwell HA: Sacroiliac joint fusion for chronic pain: a simple technique avoiding the use of metalwork. Eur Spine J 13:253-256, 2004

10. Gore M, Sadosky A, Stacey BR, Tai KS, Leslie D: The burden of chronic low back pain: clinical comorbidities, treatment patterns, and health care costs in usual care settings. Spine (Phila Pa 1976) 37:E668-E677, 2012

11. Graf C, Battisti WP, Bridges D, Bruce-Winkler V, Conaty JM, Ellison JM, et al: Good publication practice for communicating company sponsored medical research: the GPP2 guidelines. BMJ 339:b4330, 2009

12. Ha KY, Lee JS, Kim KW: Degeneration of sacroiliac joint after instrumented lumbar or lumbosacral fusion: a prospective cohort study over five-year follow-up. Spine (Phila Pa 1976) 33:1192-1198, 2008

13. Hara N, Oka H, Yamazaki T, Takeshita K, Murakami M, Hoshi $\mathrm{K}$, et al: Predictors of residual symptoms in lower extremities after decompression surgery on lumbar spinal stenosis. Eur Spine J 19:1849-1854, 2010

14. Harkness EF, Macfarlane GJ, Silman AJ, McBeth J: Is musculoskeletal pain more common now than 40 years ago?: two population-based cross-sectional studies. Rheumatology (Oxford) 44:890-895, 2005

15. Jansson KA, Németh G, Granath F, Jönsson B, Blomqvist P: Health-related quality of life (EQ-5D) before and one year after surgery for lumbar spinal stenosis. J Bone Joint Surg Br 91:210-216, 2009

16. Kim MH, Johnston SS, Chu BC, Dalal MR, Schulman KL: Estimation of total incremental health care costs in patients with atrial fibrillation in the United States. Circ Cardiovasc Qual Outcomes 4:313-320, 2011

17. Manchikanti L, Boswell MV, Singh V, Benyamin RM, Fellows $\mathrm{B}$, Abdi S, et al: Comprehensive evidence-based guidelines for interventional techniques in the management of chronic spinal pain. Pain Physician 12:699-802, 2009
18. Manchikanti L, Datta S, Derby R, Wolfer LR, Benyamin RM, Hirsch JA: A critical review of the American Pain Society clinical practice guidelines for interventional techniques: part 1 . Diagnostic interventions. Pain Physician 13:E141-E174, 2010

19. Manchikanti L, Pampati V, Boswell MV, Smith HS, Hirsch JA: Analysis of the growth of epidural injections and costs in the Medicare population: a comparative evaluation of 1997 , 2002, and 2006 data. Pain Physician 13:199-212, 2010

20. Mehra M, Hill K, Nicholl D, Schadrack J: The burden of chronic low back pain with and without a neuropathic component: a healthcare resource use and cost analysis. J Media Econ 15:245-252, 2012

21. Rajaee SS, Bae HW, Kanim LE, Delamarter RB: Spinal fusion in the United States: analysis of trends from 1998 to 2008. Spine (Phila Pa 1976) 37:67-76, 2012

22. Schulman KA, Rubenstein LE, Glick HA, Eisenberg JM: Relationships between sponsors and investigators in pharmacoeconomic and clinical research. Pharmacoeconomics 7:206220, 1995

23. Segel JE: Cost-of-Illness Studies-A Primer. Research Triangle Park, NC: RTI International, 2006 (http://www.rti.org/ pubs/coi_primer.pdf) [Accessed January 6, 2014]

24. Sembrano JN, Polly DW Jr: How often is low back pain not coming from the back? Spine (Phila Pa 1976) 34:E27-E32, 2009

25. Szadek KM, van der Wurff $P$, van Tulder MW, Zuurmond WW, Perez RS: Diagnostic validity of criteria for sacroiliac joint pain: a systematic review. J Pain 10:354-368, 2009

26. Weiner DK, Kim YS, Bonino P, Wang T: Low back pain in older adults: are we utilizing healthcare resources wisely? Pain Med 7:143-150, 2006

27. Weksler N, Velan GJ, Semionov M, Gurevitch B, Klein M, Rozentsveig V, et al: The role of sacroiliac joint dysfunction in the genesis of low back pain: the obvious is not always right. Arch Orthop Trauma Surg 127:885-888, 2007

28. Wise CL, Dall BE: Minimally invasive sacroiliac arthrodesis: outcomes of a new technique. J Spinal Disord Tech 21:579584,2008

Manuscript submitted February 25, 2013.

Accepted January 6, 2014.

Portions of this work were presented as an abstract at the 8th Interdisciplinary World Congress on Low Back \& Pelvic Pain, October 27-31, 2013, Dubai, United Arab Emirates.

Please include this information when citing this paper: published online February 14, 2014; DOI: 10.3171/2014.1.SPINE13188.

Address correspondence to: Stacey J. Ackerman, Ph.D., Covance Market Access Services Inc., 10300 Campus Point Dr., Ste. 225, San Diego, CA 92121. email: stacey.ackerman@covance.com. 